\title{
Self-medication patterns among nursing students in North India
}

\author{
Dr Divya Goel ${ }^{1}$, Dr Sanjay Gupta ${ }^{2}$ \\ 1- Dept. of Pharmacology, MMIMSR, Mullana, Ambala, Haryana, India \\ 2- Dept. of Surgery Govt. Medical College and Hospital, Chandigarh, India
}

\begin{abstract}
:
Background: Self-medication is defined as selection and use of medicines by individuals to treat selfrecognized or self-diagnosed conditions or symptoms. Self-medication can lead to various health problems like adverse drug reactions, prolonged suffering, and drug-dependence and increase resistance among various pathogens. Very few studies have evaluated its pattern and prevalence in nursing students.
\end{abstract}

Methods: A cross-sectional questionnaire-based study was conducted on the second year nursing students of nursing college of Haryana, North India. A questionnaire consisting of both open and close - ended questions related to various aspects of self-medication was handed to the students. Consenting students anonymously filled the questionnaire.

Results: A total of 122 students, three incomplete questionnaires were excluded and remaining 119 analysed. Practice of self-medication was reported by $88.24 \%$ nursing students. The most common ailment for seeking self-medication was headache (42.86\%), followed by fever (32.38\%), common cold/cough and pain abdomen. Paracetamol (59.05\%), analgesics (39.05\%), antibiotics (26.67\%), antihistaminics, and cough suppressants were most commonly used drugs/drug groups for self-medication. Among reasons for seeking self-medication, ease $(33.33 \%)$ was given as the major reason by the respondents, while $22.86 \%$, felt it give them learning opportunity. Most common source of drug information was pharmacist (51.43\%). Of the respondents $40.34 \%$ were unaware about adverse drug reactions and $48.74 \%$ were unaware about drug interactions.

Conclusions: Our study shows that self-medication is widely practiced among nursing students of the institute. There is dire need to make them aware about the pros and cons of self-medication in order to ensure safe usage of drugs.

Key words: drugs, nursing students, Self-medication, students

\section{Introduction:}

Self-medication is commonly practiced worldwide. ${ }^{1}$ It is defined as the use of the drugs by the patient on his own without consulting a medical practioner. ${ }^{2}$ It is an important component of patient's behaviour in coping with illness, especially for commonly encountered health problems, which patient believes does not require the need of going to the doctor. ${ }^{3}$ It saves time and cut down the cost of treatment, but at the same time practice of self-medication can cause harm as well. ${ }^{4 \text { Although }}$, World Health Organization (WHO) has emphasized the need of responsible self- medication for the prevention and the treatment of common illness. ${ }^{5}$ This responsible self medication is however, restricted to the over the counter (OTC) drugs, for the conditions that are self recognizable and at the same time only if the user has the information of how to take the drug, when to take, how long to take, its possible side effects, drug-interactions and when to consult the doctor. ${ }^{6}$ For practice of responsible self-medication a certain level of knowledge is required otherwise it can lead to incorrect or delay in diagnosis, increased resistance among pathogens and increase morbidity because of side effects and drug interaction i.e. drug-alcohol. ${ }^{1}$

Self-medication is not only prevalent in general population but is also common among the health care providers. Because they exposed to the knowledge of drugs, the pattern and incidence may however be different as compared to general population. In one study in India, self-medication was reported among $92 \%$ of the medical students in contrast to $59 \%$ of the non-medical students. ${ }^{7}$ A number of studies have been conducted to study the self-medication among students but a very few on the nursing students. In India, the pattern of selfmedication among nursing students remained unexplored. The present study is done to determine the pattern of self-medication practice among the undergraduate nursing students. 


\section{Materials and Methods:}

It was a cross-sectional, questionnaire-based study. A prevalidated questionnaire consisting of open and closed ended questions was used. The study was conducted in a tertiary care medical college and hospital in Haryana.

It was conducted on the $2^{\text {nd }}$ year undergraduate students of nursing, who have pharmacology as one of their subject. The purpose of the study and procedure of completing the questionnaire was explained to the students. Self-medication term was explained to the students as "the use of medicine for self -treatment without consulting the health care professionals". The consenting students completed the questionnaire in the classroom and returned it back for evaluation. The confidentiality was ensured to the students. There were questions seeking the demographic characteristics, whether students sought self-medication in the preceding 3month, if yes then illness for which medication was used, name of the medicine, drug group, type of medicine system, reason for not consulting the health care professional.

Although, students were told to fill the questionnaire on their own but still mutual influence can't be ruled out. The data was analysed using SPSS version 20.00. Descriptive data were expressed as percentage, frequency and mean \pm S.D. Chi-square test was used for testing statistical significance. A P value less than 0.05 were considered to be statistically significant.

Prior permission was obtained from the ethics committee of the institution for conducting the study.

\section{Results:}

A total of 122 questionnaires were distributed, 119 were filled completely and 3 were excluded from analysis because of incomplete information. This gave response rate of $97.54 \%$. The mean age of the respondents was $19.32 \pm 0.82$ years. The number of female students (95) outnumbered the male students (24). A total of 105(88.24\%) students reported to practice self-medication in preceding 3 months with 24 males (100\%) and 81 females $(85.26 \%)(\mathrm{P}=0.045)$. Table-1

\section{Demographic characteristics ---Table-1}

\begin{tabular}{|l|l|l|l|}
\hline \multicolumn{2}{|l|}{ Demographic factors } & $\begin{array}{l}\text { No. of students } \\
\text { N=1119 }\end{array}$ & $\%$ \\
\hline Gender & Male & 24 & $20.17 \%$ \\
& Female & 95 & $79.84 \%$ \\
\hline
\end{tabular}

It was found that headache $(42.86 \%)$ was the predominant ailment, which led to self-medication in students, followed by fever (32.38\%), common cold/cough, and pain abdomen. Drugs or drug groups commonly used for self-medication were paracetamol $(59.05 \%)$ followed by analgesics $(39.05 \%)$, antibiotics $(26.67 \%)$, and antihistaminics, cough suppressants and antiulcer drugs. Figure-1

Ease (33.33\%) was given as the major reason by the respondents for self-medication practice; followed by learning opportunity $(22.86 \%)$, time saving and cost effectiveness. Table-2 The most common reported source of drug information was pharmacist (51.43\%), followed by prior prescription, experience of prior illness, media, friend and books. Figure-2

The students knowledge about possible adverse effects and drug interactions of the drugs were also assessed, while $59.66 \%$ students had knowledge about possible adverse effects $51.26 \%$ students had knowledge about drug interactions. Table-2 $30(28.57 \%)$ of the respondents had consulted the doctors because of no improvement or worsening of symptoms.

Pattern of self-medication among nursing students-Table-2

\begin{tabular}{|c|c|c|}
\hline Characteristics & \multicolumn{2}{|c|}{ Responses } \\
\hline $\begin{array}{lll}\begin{array}{l}\text { Students } \\
\text { medication }\end{array} & \text { practiced } & \text { self- } \\
\end{array}$ & No. of students & $\begin{array}{l}\text { Students practiced self-medication } \\
(\%)\end{array}$ \\
\hline & $\begin{array}{l}119 \\
\text { F-95 } \\
\text { M-24 }\end{array}$ & $\begin{array}{l}105(88.24 \%) \\
81(85.26 \%) \\
24(100 \%) \\
P=0.045\end{array}$ \\
\hline $\begin{array}{l}\text { Diseases for which self- } \\
\text { medication is practiced }\end{array}$ & $\begin{array}{l}\text { Type of symptoms/ diseases: } \\
\text { Headache } \\
\text { Fever } \\
\text { Cough/common cold } \\
\text { Pain in abdomen }\end{array}$ & $\begin{array}{l}\text { Frequency (\%) } \\
45(42.86 \%) \\
34(29.57 \%) \\
24(22.86 \%) \\
16(15.24 \%)\end{array}$ \\
\hline Factors for self-medication & $\begin{array}{l}\text { Reason: } \\
\text { Ease }\end{array}$ & $\begin{array}{l}\text { Frequency }(\%) \\
35(33.33 \%)\end{array}$ \\
\hline
\end{tabular}




\begin{tabular}{|l|l|l|}
\hline & Learning opportunity & $24(22.86 \%)$ \\
& Time-saving & $22(20.95 \%)$ \\
& Cost-effectiveness & $20(19.05)$ \\
\hline Awareness of adverse effects & Yes (\%) & $71(59.66 \%)$ \\
$(\mathrm{N}=119)$ & No $(\%)$ & $48(40.37 \%)$ \\
\hline Awareness of drug interactions & Yes $(\%)$ & $61(51.26 \%)$ \\
$(\mathrm{N}=119)$ & No $(\%)$ & $58(48.74 \%)$ \\
\hline
\end{tabular}

\section{Discussion:}

The present study shows that the self -medication is widely practiced (88.24\%) by the nursing students of this institute. Not much data is available about the self-medication in nursing students, but other studies showed that it had been found to be up to $45 \%$ in Turkey, ${ }^{8} 88 \%$ in Croatia ${ }^{9} 94 \%$ in Hong Kong, ${ }^{10} 76 \%$ in Karachi, ${ }^{11} 87 \%$ in India ${ }^{12}$ among university students. Other study had shown the prevalence of self-medication differ among students who have knowledge of drugs from those who don't, $92.80 \%$ in students of health care group and $91.90 \%$ in students from non-health group. ${ }^{13}$ High prevalence of self-medication might be linked to the professional course as it had been noted that high level of education and professional status are predictive factors for self-medication. ${ }^{4}$

In our study it was found that the practice of self-medication was more prevalent among males than females $(P=0.045)$. This is similar to the findings conducted on the medical students in India. ${ }^{7}$ However there is dearth of data regarding practice of self-medication in nursing students so it's difficult to compare the data of this institute in the national perspective.

\section{Drugs used for self- medication- Fig. 1}

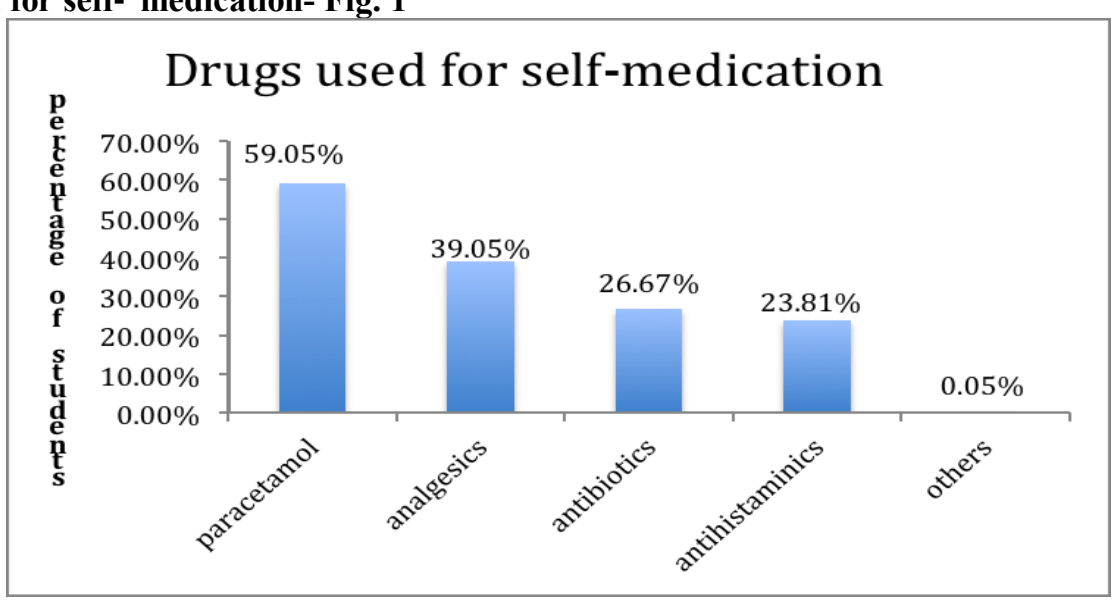

In this study most commonly reported symptoms in the 3-month period prior to study that led to the self-medication were Headache $(42.86 \%)$ and fever $(32.38 \%)$, which is in concordance with other studies that reported the most common symptom that led to self-medication in medical students, was headache (70.9\%) in Bahrain, ${ }^{5}(72.4 \%)$ in Karachi. ${ }^{11}$ However the prevalent symptoms reported in the previous study done on the medical students in India was cold and cough $(35.21 \%) \%$. It also reported that medical students self-medicate for unusual reasons like exam stress, sports injuries also. ${ }^{7}$

In this study it was noticed that the drugs or classes of drugs that were commonly used were paracetamol (59.05\%), analgesics (39.05\%), and antibiotics (26.67\%). The findings are similar to the study done earlier, which showed paracetamol (48.44\%); analgesics like NSAIDS (42.20\%), followed by antibiotics $(17.20 \%)$ were commonly used drugs. ${ }^{[15]}$ Similar results had been shown in the study done in India, drugs commonly used for self-medication were antipyretics (71\%), analgesics $(65 \%)$, antihistamines $(37 \%)$ and antibiotics (34\%). ${ }^{7}$ In contrast study done in Ethiopia reported low use of antibiotics (4.8\%). ${ }^{16}$ Only one students had taken antibiotic for 5 days, $46.43 \%$ took it for 3 days, $42.85 \%$ took it for 2 days and $10.71 \%$ reported to have taken it for one day only. In India antibiotics can be procured from drug stores without prescription, this type of practice of self-medication with antibiotics can escalates the development of resistance in microorganisms. Regarding reasons, which provoked the students to go for self-medication, ease (33.33\%) had been cited as the most common reason.

While the most common source of drug information reported was pharmacist $(51.43 \%)$, similar to study in Karachi (64.6\%). ${ }^{11}$ All these data showed that free availability of the drugs from the drug stores allure the students to go for self-medication and health authorities should make some policies to create awareness among students about the consequences of self-medication. In addition there should be strict regulation of sale of drugs other than over the counter drugs. Despite studying in detail about drugs $40.37 \%$ students were 
unaware about possible adverse effects $48.74 \%$ students were unaware about possible drug interactions of the drugs. In addition $28.57 \%$ of students had consulted the doctor after self-medication either because of no improvement or worsening of condition.

Source of information on self-medications as reported by students- Fig. 2

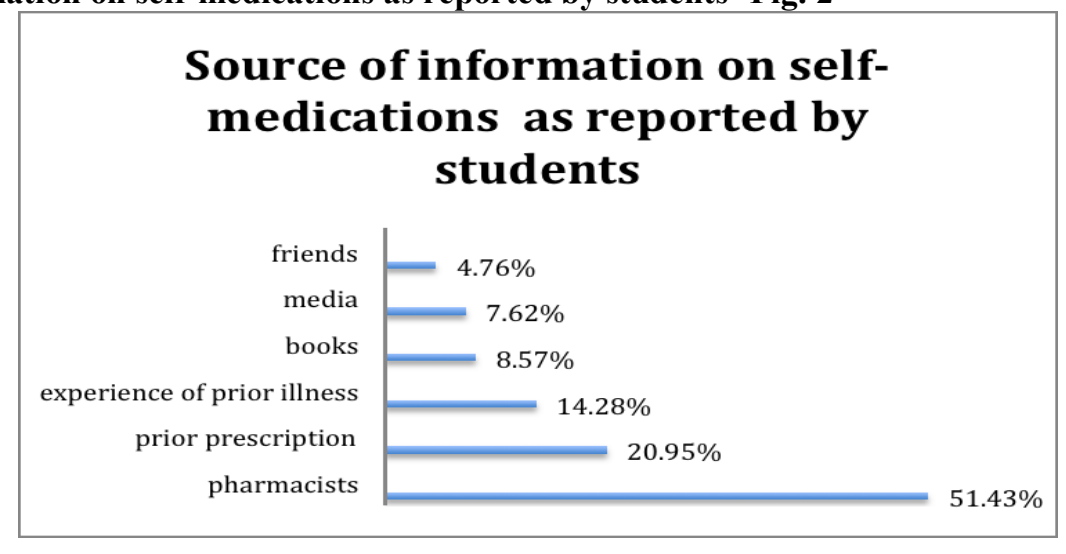

V. Conclusion

This study shows that self-medication is widely practiced among the nursing students facilitated by the easy availability of the drugs. A significant number of the students are unaware about the dosing regimen of antibiotics, possible adverse effects and drug-interactions of the drugs. Since inappropriate self-medication can cause serious harm not only to the students but also to those whom they might suggest as health providers. Nurses play a vital role in health promotion including education of responsible, informed self-medication, so steps should be taken to make them more aware about the pros and cons of self-medication, and the importance of responsible self-medication.

The limitations of this study were small sample size; response was based on self-reported data of previous three months thus prone to recall bias and absence of interventions like hazards of irresponsible selfmedication.

\section{References:}

[1]. Hughes CM, McElnay JC, Fleming GF. Benefits and risks of self-medication. Drug Saf 2001; 24: 1027-1037.

[2]. WHO guidelines for the regulatory assessment of medicinal products for use in self-medication, 2000. Available fromwww.who.int/medicines/library/qsm/whoedm-qsm-2000-1/who-edm-qsm-00 1.htm.

[3]. Figueiras A, Caamaño F, Gestal-Otero JJ: Sociodemographic factors related to self-medication in Spain. Eur J Epidemiol 2000; $16: 19-26$.

[4]. James H, Handu SS, Al Khaja KAJ, Sequeira RP. Evaluation of the knowledge, attitude and practice of self-medication among first year medical students. Med Princ Pract 2006; 15: 270-275.

[5]. World Self-Medication Industry: Responsible self-care and self-medication. A worldwide review of consumer surveys. http://www.wsmi.org/pdf/wsmibro3.pdf.

[6]. World Health Organization: The role of the pharmacist in self-care and self-medication. Available from: http://www.apps.who.int/medicinedocs/pdf/whozip32e/whozip32e.pdf [Last accessed on 2012 Dec 23].

[7]. Badiger S, Kundapur R, Jain A, Kumar A, Patanashetty S, Thakolkaran N, etal. Self-medication patterns among medical students in South India. AMJ 2012; 5: 217-220.

[8]. Buke C, Limoncu M, Ermevtcan S, Ciceklioglu M, Tuncel M, Kose T, et al. Irrational use of antibiotics among university students. J Infect 2005; 51: 135-9.

[9]. Vucic VA, Trkulja V, Lackovic Z. Content of home pharmacies and self-medication practices in households of pharmacy and medical students in Zagreb, Croatia: findings in 2001 with a reference to 1977. Croat Med J 2005; 46: 74-80.

[10]. Lau GS, Lee KK, Luk CT. Self-medication among university students in Hong Kong. Asia Pac J Public Health 1995; 8: 153-7.

[11]. Zafar SN, Reema S, Sana W, Akbar JZ, Talha V, Mahrine S, et al. Self medication amongst university students of Karachi: Prevalence, knowledge and attitudes. J Pak Med Assoc 2008; 58:214-7.

[12]. Verma, RK, Mohan L, and Pandey M, Evaluation of self-medication among professional student in North India: proper statutory drug control must be implemented. Asian Journal of Pharmaceutical and Clinical Research 2010; 3: 60-64.

[13]. Klemenc-Ketis Z, Hladnik Z and Kersnik J. Self- medication among healthcare and non-healthcare student at university of Ljubljana, Slovenia. Med Orinc Pract 2010; 19: 395-401.

[14]. Banerjee I, Bhadury T. Self-medication practice among undergraduate medical students in a tertiary care medical college, West Bengal. J Postgrad Med 2012; 58:127-31.

[15]. Journal of Applied Pharmaceutical Science 2011; 01: 183-189.

[16]. Abay SM, Amelo W. Assessment of self-medication practices among medical, pharmacy, and health science students in Gondar University, Ethiopia. Pharm Prac 2010; 2: 306-10. 